\title{
Exploring Subjectivity in Verbal Reports of Iranian EFL Learners in Institutional Discourse
}

\author{
Ashraf Haji Maibodi (Corresponding author) \\ Department of English, Science and Research Branch, Islamic Azad University, Tehran, Iran \\ E-mail: amaibodi2014@gmail.com \\ Ali Mohammad Fazilatfar \\ Yazd University, Yazd, Iran \\ E-mail: afazilatfar@yahoo.com \\ Hamid Allami \\ Yazd University, Yazd, Iran \\ E-mail: hamid_allami@yahoo.com
}

Received: 18-04-2016

Published: 01-09-2016
Accepted: 30-06-2016

doi:10.7575/aiac.ijalel.v.5n.5p.252
Advance Access Published: July 2016

URL: http://dx.doi.org/10.7575/aiac.ijalel.v.5n.5p.252

\begin{abstract}
The present study investigates Iranian EFL learners' subjectivity in single-subject retrospective verbal reports that allow the examination of the changes in the cognitive, social and affective processes involved in L2 pragmatic production. To this end, eighteen EFL learners at three proficiency levels produced verbal reports after the administration of a written discourse completion task eliciting requests and apology in asymmetrical (status-unequal) relations in institutional discourse. Qualitative analyses of students' responses indicate that sociocultural, socio-psychological and socioaffective aspects of the discourse situations influenced both their pragmalinguistic and sociolinguistic choices and negotiation of lexical and grammatical choices in planning the speech acts of requests and apologies. Apparently, the degree of sociocultural accommodation to the L2 pragmatic norms may be a matter of choice as of ability.
\end{abstract}

Keywords: learner subjectivity, pragmalinguistic, sociolinguistic, retrospective verbal reports, institutional discourse

\section{Introduction}

In the field of interlanguage pragmatics (ILP), substantial studies combining retrospective verbal reports (RVRs) have revealed the cognitive processes learners use in pragmatic production. RVRs are subsequent to the task and prompt learners to report on the thoughts they had during task completion (Jourdenais, 2001). This refers to information on how learners assessed and planned their speech act utterances, their language of thought, the planning of their responses and how they selected and retrieved language forms (Cohen, 2013; Cohen \& Olshtain, 1993; Felix-Brasdefer, 2006, 2008; Hassall, 2008; Trosborg, 1995; Woodfield, 2010, 2012). As a form of introspection of verbalized thought processes of participants these reports can also be invaluable tools in exploring the competence underlying speakers' performance (Kormos, 1998) because they aim to provide insights into the reasoning behind learners' written or spoken behaviors during language production (Jourdenais, 2001; Gass \& Mackey, 2000).

The theoretical basis for verbal reports lies in an information-processing theory of memory (Ericsson \& Simon, 1993). The advantage of administering RVRs immediately after the cognitive task is that they will help to minimize the possibility that participants may start relying on inferences rather than reporting what happened. Furthermore, RVRs can also help to assess the level of awareness of the participants in a task designed to help them to attend to certain aspects of the input. Ren (2013) argued that "When designed and executed with caution, particularly in combination with other data collection methods, the RVR can provide researchers with added in-depth insights into participants' pragmatic knowledge" (p. 576). Understanding such strategies and processes has been deemed crucial in drawing inferences about test-takers' abilities which are responsible for their performance. For example, Cohen and Olshtain (1993) found data from the RVRs indicated that lack of pragmatic knowledge led to learners' difficulties in communicating pragmatic intentions. Moreover, for empirical studies, the effect of instruction and the role of attention in second language acquisition (SLA) "collecting data through verbal reports can give more accurate, detailed information that was impossible to obtain by means of the pretest-treatment-posttest experimental design" (Camps, p.202). This methodological improvement has strengthened the empirical support for the "noticing hypothesis" (Schmidt, 1993).

However, there is a lot of controversy regarding the validity and reliability of the RVRs that are widely used in language-learning research (Gass \& Mackey, 2000; Jourdenais, 2001; Ren, 2013). RVRs may not accurately reflect 
participants' cognitive processes or there is a possibility that learners may provide inaccurate reasons for their thoughts. The validity of the RVR may also be affected by over reporting (Nisbett \& Wilson, 1977) and learners may hypothesize regarding the cognitive process rather than report actual behavior. That is, they may report more than their cognition. For example, particularly in the case of high-task complexity (Ericsson \& Simon, 1993; Gass \& Mackey, 2000) it has been noted that some information on cognitive processes may not be accessible by verbal reports (Seliger, 1983). On the other hand, Camps (2003) believed that lack of verbalization does not necessarily mean that learners are not aware of the elements they are processing.

Learners approach the task of learning another language in different ways, according to various individual characteristics. One of these characteristics is the beliefs ((Horwitz, 1999) that are really important because success depends more on what goes on inside the learner than on techniques and materials used and the attitudes they develop will motivate the learner to act in a specified manner. EFL students have different needs, preferences and perceptions that are recognized as a significant contributory factor in the learning process and ultimate success and imposition of change upon these factors can lead to negative reactions. Learners work selectively within their learning environment from their conceptualizations of the conditions and of the language to be learned that they believe to be facilitating or hindering their learning and also upon the linguistic and communicative data made available to them in that environment.

Although verbal reports elicit specific information regarding learners' cognitive processes, to date, only few studies on L2 pragmatics have examined learners' cognitive processes in the performance of speech acts (Cohen \& Olshtain, 1993; Fe'lix-Brasdefer, 2008; Hassall, 2008; Ren, 2013; Woodfield 2010, 2012). Hence, the present study that was based on a larger research project (Haji Maibodi, 2016) went a step forward to use the RVRs as a springboard for discussion in search for instances of learners' subjectivity and agency in relation to speech act performance. The focus of the present study was on the intentional and conscious responses given by participants to requests and apologies in institutional discourse that are likely to be influenced by sociocultural, socio-affective and socio-psychological aspects of the context. To this end verbal reports were administered to measure: (1) the cognitive information that participants attended to during interaction; (2) the selection of the language of thought for planning and executing a speech act in status-unequal situations; and finally (3) to understand the role of noticing in ILP. The objective of this study was to find qualitative and pedagogical evidence to the following research question:

- How do EFL learners in the three academic levels (undergraduates, postgraduates and PhD students) explain their language awareness to deliberately converge or diverge from perceived FL pragmatic norms?

\section{Review of Literature}

\subsection{Interlanguage Pragmatics (ILP)}

ILP is the investigation of non-native speakers' comprehension and production of speech acts, and the acquisition of L2-related speech act knowledge (Kasper \& Dahl, 1991). The distinction between sociopragmatics and pragmalinguistics (Leech, 1983) is well accepted in pragmatics research. Pragmalinguistic competence is primarily linguistic knowledge for realizing and understanding the speaker's intentions (e.g., knowledge of syntactic structures and semantic formulae for a speech act) and accounts for 'the more linguistic end of pragmatics' (Leech, 1983). Sociopragmatic competence, on the other hand, is knowledge of sociocultural norms and conventions and the ability to evaluate contextual factors in understanding and expressing intended meaning (e.g., semantic content and choice of politeness strategies) and described as 'the sociological interface of pragmatics', referring to the social perceptions underlying participants' interpretation and performance of communicative action (Leech, 1983).

\subsection{Institutional Discourse}

Institutional discourse, as an important source of spontaneous discourse in ILP research, is the talk that occurs in the course of carrying out an institution's business, usually between an institutional representative and a client (e.g., faculty advisor and graduate student). It is the type of discourse, which is authentic and consequential, and at the same time can be compared to many other samples taken from the same setting. This type of interaction involves an orientation by at least one of the participants to some core goal, task or identity (or set of them) conventionally associated with the institution in question (Bardovi-Harlig \& Hartford, 2005). This type of talk usually takes place in relatively fixed locations often at predictable times through the scheduling of appointments or the hours of operation within the institution (Ellis, 2008) and helps in data collection because the nature of such discourse topics can be anticipated in advance (Bardovi-Harlig \& Hartford, 2005, p. 15).

\subsection{Speech act of Requests and Apology}

For the present study, the choice of the two speech acts of request and apology in institutional discourse was based on the following considerations:

1. Requests, as pre-events (face threatening acts) (Uso-Juan, 2010; Woodfield \& Economidou-Kogetsidis, 2010; Woodfield, 2010) affect the face of the hearer and express the speaker's expectation of the hearer about a prospective action, verbal or nonverbal.

2. Apologies, as post events (face saving acts), (Bergman \& Kasper, 1993; Blum-Kulka, House \& Kasper, 1989; Cohen \& Olshtain, 1993; Trosborg, 1995) counteract the speaker's face signaling the fact that the event has already taken place (Brown \& Levinson, 1987). 
3. These speech acts are the most-studied in cross-cultural and ILP and are particularly interesting for a developmental investigation, as they are utterances that EFL learners normally make in their institutional discourse.

\subsection{Speech Accommodation Theory}

The speech accommodation theory (SAT) was devised to explain some of the motivations underlying certain shifts in people's speech styles during social encounters and some of the social consequences arising from them. This theory (Beebe \& Giles, 1984) originated in order to elucidate the cognitive and affective processes underlying speech convergence and divergence. They maintain that L2 speaker' social variables (e.g., objectively defined social categories such as age, gender, ethnicity, and socioeconomic status) alone would not determine their speech behavior; rather, L2 speakers' "own subjective attitudes, perceptions of situations, cognitive and affective dispositions, and the like may interact to determine their speech outputs" (p. 5).

\subsubsection{Learner Subjectivity; Agency}

Following Weedon (1997) in this study "subjectivity" is defined as "the conscious and unconscious thoughts and emotions of the individual, her sense of herself and her ways of understanding her relation to the world" (p. 32). From a sociocultural point of view, learners are social beings loaded with their own views and perceptions of the world, values, beliefs, morals, feelings, and personal principles. Their subjectivity, as Ishihara (2006) believed may be influenced largely by their own community norms and practices that may sometimes be incongruent with the norms of the second language community.

The construct subjectivity is essentially synonymous with that of social identity and is used interchangeably. According to Norton (1997), identity refers to "how people understand their relationship to the world, how that relationship is constructed across time and space, and how people understand their possibilities for the future" (p. 410). And the term "subject" is a particularly helpful one, as it reminds us that we are often "subject of" a set of relationships (i.e. in a position of relative power) or "subject to" a set of relationships (i.e. in a position of relative powerlessness)" (Norton \& Toohey, 2011, p. 417). Individuals make personal meaning in the immediate social context where their individual dispositions play a pivotal role in the formation and reformation of subjectivity (Ishihara, 2008).

Subjectivity in sociocultural terms has also been identified as its agency-giving nature in its relation to power and institution (LoCastro, 2003; Norton, 1997) and can be defined as a self-reliant, independent, or self-defining capacity to operate with volition and power to bring about an effect, change, or decision. 'Agency' is not simply an individual character trait or activity, but a contextually enacted way of being in the world and has the potential of being related to issues such as volition, intentionality, initiative, intrinsic motivation and autonomy (van Lier, 2008).

\section{Method}

\subsection{Participants}

The verbal reports for this study was gathered from 18 students - males $(\mathrm{N}=9)$ and females $(\mathrm{N}=9)$ selected from three TEFL groups (eight senior undergraduates, six postgraduates, and four $\mathrm{PhD}$ ) from two universities. Their ages ranged from 20 to 35 years. Demographic information of the students was related to gender, age, nationality and marital status. The information showed that they had started studying English at school when they were about twelve years old (three years in guidance school and four years at high school) and at the age of eighteen, they had taken a serious interest in the language. None of the participants had ever been to an English speaking country like the U.S.A, U.K or Australia for at least three months. Neither did they have native speakers as teachers nor had specific instructions in pragmatics or speech acts before or during this study. The rationale behind choosing university students as a source of data collection was a convenience of sampling as well as following from most of the prior studies (Woodfield \& EconomidouKogetsidis, 2010) on speech acts in which the participants had been university students. Nevertheless, caution is needed and that is, not to generalize from a group of students to the full range of an overall population.

\subsection{Procedures}

Initially, the proficiency levels of the participants were evaluated through the Oxford Placement Test (OPT). Students' were divided to three proficiency levels based on the scores obtained on the OPT - low intermediate, upper intermediate and advanced-according to the standards set by the test itself. Although the OPT is a standard measurement, the KR-21 formula, the reliability index for the OPT in the present study was found to be 0.85 , which is considered an acceptable level of reliability.

The RVRs for the present study focused not only on the cognitive processes involved in the planning and execution of requests and apologies but also to study learner's subjectivity and agency after the completion of the Written Discourse Completion Tasks (WDCT). Participants were asked to report on the thoughts they had while they were completing the tasks. The speech act situations concentrated only on the discourse that normally takes place between the faculty and the students. The scenarios represented an area of institutional discourse with the aim that the students will address a professor of a course within their major and could be occasions that they may encounter outside the classroom. The following Table1 gives the list of speech act situations. 
Table 1. List of situations for written discourse completion tasks (WDCTs)

Situation 1: rechecking the paper (request) Situation 6: being late for class (apology)

Situation 2: computer to be repaired Situation 7: asking for interview (request) (request)

Situation 3: spilling tea on borrowed book (apology)

Situation 4: borrowing book (request)

Situation 5: losing the book (apology)
Situation 8: missing appointment (apology)

Situation 9: asking for extension for term project (request) enhanced prompt

Situation 10: accident on the stairway

(apology) enhanced prompt

The verbal reports administered were based on students' responses to the WDCTs and included both fixed and datadriven questions (Woodfield, 2010). In the verbalization process, Ericsson and Simon's (1993, p. 198) fixed question helped to formulate the four types of statements: intentions, cognitions, planning and evaluations. These questions included, 'what did you notice about the situation?'; 'what were you paying attention to'; 'were you satisfied with your answer?' In order to avoid asking leading questions, Jourdenais (2001, p. 357) believed that researchers should ask "focused yet open-ended questions and providing contextual cues" will help the learner to reconstruct the situation. For example, 'In task X you said that you felt (utterance) was more polite, can you say more about this?' Moreover, participants in this study were also asked to indicate the language of their thoughts and were given a choice to choose their language -Persian or English - so that they will not be under any pressure. In line with Felix-Brasdefer (2008, p. 203) findings showed that learners switched the language of thought to English when having trouble with pragmalinguistic information. For example,

\section{Which language were you relying on in making your decision: Persian or English?}

(1) I tried to concentrate more on my English knowledge because it had engaged my mind and I found it much easier to think in English.

(2) Due to culture gap and the way of thinking, I was searching for the exact words in English.

In this report, only a few samples are taken into consideration and data analyses of the RVRs centered on the sociocultural, socio-affective and socio-psychological aspects of the context.

\section{Results and Discussions}

Following Woodfield (2010, p. 9) an initial coding framework was established. Within this framework, three discrete categories emerged inductively: orientate, solve and evaluate. Initially, the RVRs were coded according to (i) participants' language of thought; (ii) learner difficulties with the methodology; (iii) sources of learners' pragmatic knowledge and (iv) knowledge statements relating to learners' pragmalinguistic or sociopragmatic knowledge. As such, 1,800 verbal reports were taken from the students at the three proficiency levels. All learners orientated to the sociocontextual aspects of the WDCTs reflecting the universal pragmatic knowledge brought to the task (Kasper \& Rose, 2002). Analysis revealed that learners evaluated the appropriateness of linguistic strategies in response to the task. This was in line with 'Orientation', which refers to those episodes where participants attend to task goals, task language, and contextual aspects of the WDCTs (Woodfield, 2010).

In general, pragmatic competence in the L1 is the result of language socialization (Kecskes, 2015). The inference is that learners have a certain level of pragmatic comprehension ability, and any variations in the responses could be due to sociocultural considerations of the task, and to an extent linguistic consideration. Data from the present study supported Woodfield (2010) in that RVRs relating to learners' sociopragmatic knowledge evidenced not only learners' assessment of the relative importance of different aspects of the situation but also ways in which such assessment mediated pragmalinguistic choices. Interestingly, learners' analysis of the situational variables such as the interlocutor's age, gender and status of the interlocutor could have been a vital factor that mediates L2 socialization and might constrain L2 learners' opportunity or desire to participate in the community of practice.

Was there anything in the situation that you felt you should consider when you decided how to make your request or to apologize?

(1) I have had such experiences so many times. I know it is useless making such a request. You feel so helpless and ashamed!

(2) Very often, when I had such a problem I would always go to my lecturer and talk to him. But here I had to write it out. Making a request or apologizing is sometimes very difficult.

(3) What I could say orally in Persian was difficult to write in English. Finding the proper words to show my intentions was very difficult (low intermediate).

Although governed by socio-psychological notions of appropriateness, in line with Ren (2013), learners reported paying increasingly more attention to socio-pragmatics when they responded to each situation of the task. Supporting previous studies (Cohen \& Olshtain, 1993; Fe'lix-Brasdefer, 2006: Hassall, 2008; Woodfield, 2010, 2012), collected data 
suggested that learners focused not only on grammar and vocabulary but also on their L1 socio-pragmatic and pragmalinguistic knowledge and politeness. Especially, RVRs of the low intermediates indicated the influence of perceptions of status-differences between student and tutor (Fukushima, 2000) on planning processes. This was evident in these learners opting for direct strategies indicating that they had difficulties in selecting the appropriate forms according to appropriate levels of directness and indirectness in speech act production. There was evidence of formal instructions on pragmatic choices (Hassall, 2008; Woodfield, 2010). Students reported thinking the utterance through quickly in Persian (L1), before producing it in English (L2), because they felt that they were more confident in their L1 rather in the $\mathrm{L} 2$.

\section{What were you paying attention to? The type of information you wanted to give.}

(1) Trying to decide between 'can you/will you' and 'could you/would you' was difficult. I thought using these words is too rude for my professor.

(2) In most of the situations, I was thinking about how the person is going to react to my answer. The reaction of my lecturer and professor is very important.

RVRs show that there are many linguistic elements available to a learner that may not be equally used during online processing. For example, the form and the word order will differ largely between the L1 and L2.This highlights the complexity of language processing demands in speech act production for learners and focuses on the key role of noticing the input into L2 learners' pragmatic development (Schmidt, 1993). Ericsson and Simon (1993) believed that training learners to provide protocols might assist them in providing more complete and accurate portrayals of their behaviors. Moreover, Uso-Juan and Martinez-Flor (2014) argued, "RVRs will help researchers to obtain learners' insightful information (i.e. the planning and execution of speech act production, pragmatic knowledge, as well as the attended aspects when uttering speech acts) that is not accessible through an analysis of DCT response data alone" (p. 117).

The second category referred to as 'Solution' related to those language-related episodes (Swain, 1995) where learners generated hypotheses in the form of linguistic strategies in response to the WDCTs and attempted to find a resolution (Woodfield, 2010). Previous ILP studies employing RVRs asked individual learners to retrospect on their choice of forms during oral role-play (Cohen \& Olshtain, 1993; Fe'lix-Brasdefer, 2008; Hassall, 2008).

(1) We had learnt that requests start with 'would you/could you...' I knew I was writing to my lecturer. Mr. Moradi is very strict but also kind.

(2) She is very nice but in such cases, I have no experience. Will you/could you...no I don't like to beg or plead for something. I like my requests and apologies to be sincere and reasonable.

(3) Writing is difficult for me, especially to my professors in the university. I felt so weak while making requests and clumsy and stupid while apologizing (female-advanced level).

These participant-initiated reports (Woodfield, 2010) were instrumental in revealing learners' grammatical and lexical difficulties in formulating appropriate written responses to the task.

L2 learner agency has been reported as a form of resistance to accept sociocultural practice of a target language community. When L2 learners find a conflict between their belief and a normative practice of a target language community, they resist emulating it (Ishihara, 2006). The third category 'Evaluation' is related to those utterances in which learners evaluate the appropriateness of linguistic strategies in response to the task (Woodfield, 2010). For example, most of the written productions did not have 'alerters' or 'attention getters.' They did not start with 'Dear' a term that Iranian EFL learners have not come to accept as a 'neutral' form in opening all letters. Even there was no use of 'Good morning/afternoon.' However, some low proficient learners opted for the informal language of 'Hi', 'Hello' or even a simple 'you.' Neither did they have a closing for their responses, like 'thank you' or 'sincerely' or 'respectfully.' Much of the language used to accomplish these purposes is in fact are quite formulaic and conventionalized and students were not aware that these rules have to be adhered to even in writing.

Did you open your writing with 'Excuse me, Sir, or Excuse me, Madame'? Why/why not?

(1) No. I am sorry I forgot what I had to say at the beginning.

(2) I started with "excuse me." I should have written "Dear." How can I say, "Dear Professor, will you do this for me...?"

(3) Some of your situations wanted an apology. How can I say, "Dear Professor, I am sorry I am happy to tell you that I lost your book" is this correct? Or "sorry, I spilt tea on your book."

(4) I cannot say, "Hello, Sir I lost your book. You see I am sorry." I am not a child. Just imagine, "Sorry Madame for pushing you down the stairs..."

These statements show that utterances were related to participants' language of thought, evidence of self and their difficulties with the methodology. Bardovi-Harlig and Hartford (1990) believed that when considering face-to-face office hour consultations, students would be expected to follow a certain social protocol, which includes greetings, some small talk, and leave-taking at the verbal level. These findings revealed that learners opportunity to produce 'comprehensible output' (Swain, 1985) will create the means for them to 'notice the gap' in their interlanguage ability which will later on help them to make adjustments in order to approximate the TL pragmatic norms. 
In Persian, politeness is achieved mainly through the use of pre-posed supportive moves in which the request is likely to start with an apology, a phatic inquiry, an excuse or even a compliment. Learners of a foreign language already know how to be polite within their own language and culture, but in their attempts to transfer their native conventions to the target language, they may run into unexpected problems. Kecskes $(2015$, p. 4) believed "pragmatic rules (language use rules), however, are different: not following them may cause misinterpretation of linguistic behavior and many different reactions from the hearers." However, pragmatic function cannot be completely learned even if learners notice what specific term is used for addressing someone; learners are required to recognize why that particular form was used in relation to the social context of the interaction (Schmidt, 1993).

In trying to understand how well students comprehended and responded to the speech act situations a few instances were observed. For example, in taking responsibility for committing an offense that necessitated an apology, males felt embarrassed to apologize. In order not be considered as a careless or clumsy person they preferred to settle the matter without losing face. As Kecskes (2015) believed, "People, no matter how many languages they speak have one pragmatic competence which is modified dynamically depending on the exposure to different languages and cultures and individual preferences" (p. 2).

Surprisingly, the frequent use of 'upgraders' by most of the males showed they did not feel obliged to be more polite. For example, "Hi Doc! Are you sure you corrected my paper?" "Hi lady, sorry for pushing you." Previous studies have shown the learning environment to be significant in the development of L2 learners' pragmatic awareness (BardoviHarlig \& Dornyei, 1998; Schauer, 2006; Woodfield, 2012). Furthermore, evidence from cross-sectional studies examining learners' variation of strategies according to social status (Trosborg, 1995; Rose, 2000) suggest that learners may take time to develop appropriate mapping of linguistic forms to social categories.

(1) In Iran, we are very careful when making formal requests. It is difficult for most of us.

(2) No, I do not feel ashamed to say 'I am sorry.' But I can never say 'Dear' especially to a male... "Dear professor I lost your book."

(3) I will not apologize or even make an unnecessary request. But if I have to I will think about it (upper intermediate male).

Pragmatic rules of language use function like suggestions and/or recommendations by the members of a speech community, which are based on norms, behavioral patterns, conventions and standards of that community (Kecskes, 2015). Beeman (2001) observed, "The basic dimensions of Iranian society are not terribly complex in a structural sense, but they provide for a rich play of linguistic expression" (p. 40). Few societies take the obligations of status as seriously as the Iranian society.

\section{Borrowing a book from your lecturer and then losing it.}

(1) No, I will never borrow a book from my lecturer. No, I will not do it. Then to lose the book. At the university the next semester, you may have some classes with the same lecturer. I cannot be so careless. I do not know how to say sorry.

\section{Accident on the stairway}

(2) I will not write and say I am sorry. I will go and see her personally.

(3) Imagine pushing an aged professor and simply saying, "I am sorry." It is really ridiculous.

In Iranian life, there are orientations that are positively valued, and others that are negatively valued (Beeman, 2001). Learners' answers demonstrated the influence of considerations of status and power differences on linguistic choices. O'Shea (2000) observed, "All Iranians measure themselves to a great extent by the honor they accumulate through their actions and social interrelations" (p. 101).

How did you see your relationship with the person you were communicating with? Was it intimate, formal or informal? Please explain.

(1) Yes. I have experienced such situations so many times. I knew that I was writing to my lecturer. It is a very formal situation. I think it is much better than being face-to-face with the person. But I am not good in writing.

(2) Some of the situations were really embarrassing; yes I would write what I wanted to say orally. There was no intimacy at all.

Female participants seemed to be more pragmatically socialized than men. Analysis of their responses showed that they focused on the context and based on the beliefs they hold about language learning they will approach the task according to various learner characteristics.

\section{Extension for paper}

(1) As it is, my professor thinks that females are too lazy. No, I would never make such a request. I would stay up the whole night and get done with it.

(2) Oh! He is very strict. As a PhD student, I do not want my professor to think that I am careless or lazy. I am always very careful when I approach my professors.

Iranian EFL learners experience a range of linguistic difficulties in formulating speech acts (requests and apologies) especially in academic contexts. In line with Hassall (2008), in the planning and execution of the speech acts findings 
from the RVRs indicated a range of thoughts: these included verbal planning; pragmatics (i.e. politeness/social appropriateness); conversational management and emotion/affect. For example, low intermediate learners reported thinking about pragmatics much less often than they reported thinking about the linguistic planning of the speech act. Conversely, unlike Felix-Brasdefer (2006, p. 21), findings showed that the upper intermediates and advanced level reported thinking about pragmatics more often than thinking about linguistic planning. They were aware of the speech act situations and their language clearly focused on the message and varied according to the socio-affective aspects of pragmatic norms.

\section{In those situations you wanted to make a request, did you think you are in a position to insist something?}

(1) No. I do not think I will be foolish to let such things happen. The answer I give is important because in the future I may have some courses with that professor. I don't like somebody to think that I am a careless and irresponsible.

(2) For me as a girl I do not like to ask my lecturers to do something for me. No, I will never insist. Of course, I will be polite and think before I ask for something.

Persian has its own honorifics and that honorifics are associated with politeness is often taken for granted. Today modern Persian shares with English a rich repertoire of speech act strategies, which is fully exploited in actual use. However, it must be noted that pragmatic competence is largely governed by the attitudes developed by the person. For many, group harmony and solidarity represent fundamental cultural values. In all institutional interactions conforming to the institutional norms (Bardovi-Harlig \& Hartford, 2005) involves the use of mitigating strategies to soften the threat incurred to one's face or one's public self-image in communication.

Students evaluated the speech act situations in accordance with choices of linguistic forms for politeness and searches of appropriate content for supportive moves and appropriate lexico-pragmatic items (Woodfield, 2010). Although their responses to the questions were strongly influenced by L1 sociopragmatic knowledge in line with Bialystock (1993) it can be understood that EFL students do have the pragmalinguistic knowledge to form an appropriate request or apology but they have not yet gained full attentional control over that knowledge. However, it must be noted that certain aspects of L2 pragmatics - pragmalinguistic and sociopragmatic- do not develop sufficiently without instruction. Apparently, learners who learn the language in a classroom outside the target culture appear to be less sensitive to appropriateness and place more importance on grammatical accuracy instead (Bardovi-Harlig \& Do“rnyei, 1998).

Analysis of the responses showed that 'noticing' or 'understanding' (Schmidt, 1993) the input had not taken place especially for many of the low intermediates. Difficulties in retrieving appropriate forms were identified. Either they were not aware of the target structure, or some may have been but they did not verbalize their awareness. Under the 'Noticing Hypothesis', when L2 learners encounter problems to communicate their message (i.e., with their grammar), they notice the problems; subsequent input exposure would then help learners notice the gap between their interlanguage and the target language model (Schmidt, 1993).

\section{Do you think you need instruction in pragmatics?}

(1) I do not know. We learn English forms and speech patterns from our books. But I know it is not enough. I think I have to watch more English films and video clips. Yes, we need proper instructions.

(2) I need to learn the appropriate words, appropriate expressions, according to the situations when I request or apologize. Probably, if I knew how to apologize or make a request to your professor. The problem was with how to say.

However, findings suggest that not all input that learners are exposed to is available to the learner's developing linguistic system.

In a situation you had to apologize what words did you choose to show that you would make up for the situation-compromise?

(1) Trying to apologize in English is very difficult for me. In Persian, it is much better. How can I tell my teacher that I am truly sorry in English? I do not know the proper words.

(2) As a male, I am proud to tell you that I will apologize whenever I have done something wrong. It is much easier to apologize in Persian. It sounds more sincere. But never for an incident I did not do on purpose.

Essentially, institutional discourse is marked sharply by the distinction that is held constant between power, social distance and relative imposition. Students are aware of the type of conversation that normally takes places in the exchanges between the faculty (lecturer or professor) and the student at large. Considerations of status differences and social power are significant and these sociolinguistic considerations clearly influenced learner perceptions reflecting performance in varying degrees.

Please think of the situations once again. How serious or important were the situations?

(1) The situations were the ones that we normally experience in our university. But personally, I will never let such things happen.

(2) The status and the social power of my lecturer at the university are very important for my future. I have always been polite in my life and I will never misbehave either in words or in actions. 
According to Hassall (2008) verbal reports, ask learners to report whatever they were thinking and then examine those reports to gain insights into what they know about pragmatics and how they acquire pragmatic knowledge and ability. In response to:

How did you see the situations? Which language was easier-English or Persian when you were writing the answers? Why/why not? Those students who felt that they diverged from the target language norms wrote:

(1) I am an Iranian and I am living in Iran. I am studying English but it is not my mother tongue, I do not think in English all the time. Like an Iranian, I will approach my professor and tell him what happened.

(2) I can never be like an American student. In Iran, our lifestyle even the way we speak, think and act is different. When I had to make a request or apologize, I was thinking of my professor who is also an Iranian like me.

(3) Yes I did. Because when I want to write, I have to think of the words to be used. If I could answer in Persian, I knew what to say and how to say it.

Do you think there is a difference between a teacher, tutor, instructor, lecturer and a professor? What is the difference?

(1) In Iran there is great difference regarding social position and prestige. I can talk to my schoolteacher very, very easily but in the university, our lecturers do not want to understand us.

(2) I can ask my schoolteacher for something. But here I have to be careful when I ask something from my professors. We are young and many things will happen.

From the above responses, it is clear that many of these learners associated their language use with their personality and social identity rather than with the foreign language itself. Moreover, those students who were detected as the divergent group believed that their response depended on the person to whom they were writing. Although the idea of always assessing the social relationship between the speakers was second nature to language speakers, the divergence group seemed to have based their assessment more on their L1 norms. Interestingly many of the male students chose to use the values of their Persian culture as the basis of their performance in L2.

Did the hearer's status/position affect your language and the way you addressed him/her?

(1) I knew I had to write to my lecturer. I was searching for the correct words. I tried to think in English. I wanted to use Persian expressions. Writing in English is difficult.

(2) It is easier to say 'I'm sorry' but asking your professor, 'will you...?' 'Can you....' is not easy. I will talk to my lecturer. As a PhD student, I did not want to be careless or make use of some excuses that will show how careless and stupid I am.

Pragmatic awareness has been described as important in the generation and negotiation of meaning. It has been engaged when speakers evaluate context in their formulations of certain speech acts, such as (Bergman \& Kasper, 1993). Pragmatic norms are believed to be a range of tendencies or conventions for pragmatic language use that are not absolute or fixed but are typical or generally preferred in the L2 community. The pragmatic difficulties reported in the RVRs indicate the importance of acquiring L2 pragmatic knowledge. Learners' judgment of L2 pragmatic norms and perception of their own language and their attitudes of the learned language had a determining influence on language use. For example, in contrast to Hassall (2008) the upper intermediate learners in this study reported thinking about both the pragmatics and linguistic consequences of their language.

What do you think native speakers of English would say?

(1) Yes, I regularly watch American movies and lifestyle. But I was not sure whether an American will respond like the way I did. Remember that they are native speakers of English and they have a full command of the language.

(2) For me the situation was in an Iranian context and as a Persian speaker, I was careful that I would not hurt my professor's feelings. I have to be sure that he has positive impressions about me. Writing in English is difficult for all of us.

(3) Americans will not think like me. And even if I want to be like them in the university this type of behavior will not be approved. In America, I think you are free to express yourself more directly. I heard about this from my friends who study there.

(4) In our society, requests to friends are usually made straightforwardly. However, I think American society values individualism and people do not like to interfere in other's freedom of act or privacy. Here we are closer-we care.

In line with Hassall (2008) and Ren (2013), acquiring pragmatic knowledge can also be a major task for the adult L2 learners. Hassall (2008, p. 79) believed that FL learners, even when performing pragmatically sensitive tasks, pay more attention to expressing their propositional message with adequate clarity than they do to being adequately polite. These tasks still demand a good deal of conscious effort from them and so consume most of their language processing capacity. This means they are unable to pay more attention to pragmatics without suffering cognitive overload.

Students' responses to the speech act situations were not based on the instructions they had received, but rather on their created intentions. They reported that they had gained this knowledge through their use of language both inside and outside the classroom. As Sharifian (2013) observed, many learners bring the conceptual system that they have developed while learning their L1 into the learning of an L2, assuming that every single unit of conceptualization in 
their repertoire has an equivalent in the conceptual system associated with the L2. Bialystok (1993) argued that acquiring knowledge is of relatively minor importance for adult L2 learners of pragmatics. They generally produce inappropriate utterances not because their knowledge is deviant but because they cannot access it rapidly enough to use it when they need it.

(1) Do you mean the language? Yes. I think Americans are friendlier with their professors. I remember a reading on 'Culture Shock' there you see the difference.

(2) I understood the situations but I did not see anything serious about the events. We are young and many things will happen. Our lecturers too have to be understanding. Why don't they want to think that all that we do is unintentional?

In different social situations, people engage actively in communication with different interlocutors and in fact, experience self- identity shifts because of their English learning experience. For example, advanced learners because of their individual differences (language experience, age, gender) seemed to be more self-confident in their responses. No doubt, their RVRs revealed features of self-identity or subjectivity. They largely appeared to emulate perceived FL norms because they were aware of the negative repercussions of diverging from FL pragmatic norms, yet sometimes still opted to express their subjectivity by resisting those norms. These were the responses given to situation 1 (see Table 1) by three female-advanced learners:

(1) Excuse me, Dr. G. I saw my marks and I am not happy with it. I think I have done better and I deserve something better. My paper has to be rechecked.

(2) Good morning. Dr. A, I had done my level best for my linguistics exam. But there seems to be some problems about my marks. I think there is discrimination because of my age or because of that ...

(3) Dear Dr. F, I had some problems but I do not think these are my marks. Will you kindly allow me to see my paper?

Interestingly, one of the factors that determine the relative status of individuals in the Iranian society is gender. In this social structure, there are asymmetries between men and women with respect to power, status, and autonomy and role visibility. Iranian women are expected to be more polite and use honorifics more than men to maintain their composure and dignity and they are criticized easily for being impolite or behaving inappropriately and sometimes, these criticisms can be severe too. Students were told that their responses seemed to be rude. Their response was: (interview)

(1) You are right! But you see I am a teacher too and I am not a lazy student. I know what it means to be partial. My Professor knows me very well. I have been pushed around a lot. They do not treat women properly in classes. I feel so hopeless when I have to make a request.

(2) I have always felt this discrimination between me and the other students who are much younger than I am. I can understand how a student will feel.

(3) I have always been on time in submitting my assignments. But I cannot understand why my professors behave like this. Someone has to tell them to be just and impartial.

Appeal to hearer for understanding and leniency may signal warmth, intimacy, solidarity, and common ground. Supporting Ishihara $(2006,2008)$ the RVRs show a defensive orientation towards saving one's own face by justifying or explaining the reason for their failure. The learner perceives the language (a linguistic expression in context) as it relates to him/her and at the same time, reexamines his/her sense of identity in light of the meaning perceived ( $c f$. van Lier, 2008). In exercising their agency, learners are making an effort to make an initiative to be heard, to be original by saying something new and different. Norton (1997, p. 410) argued that learners are in search for a desire for recognition, a desire for affiliation, and a desire for security. Apparently, students seemed to rely on their beliefs, values, and personal principles (i.e., equality beyond social status/gender) that they held under those circumstances and applied these standards to interpreting the speech act situations and using the FL in those particular contexts. In contrast to females whose subjectivity was reflected as self-identity, males' notions of identity were mostly related to their language and culture. This initiative taking of learners open up new pathways for teaching and learning.

From the RVRs, it can be understood that learners are situated in their lives and their learning contexts differ from one another. In order to get their message across it appears that learners first focus their energies on the basic lexical and syntactic elements of the particular language before they engage in mitigation. Cultural conceptualizations may not be equally imprinted in the mind of every individual member of a cultural group but are rather more or less shared between the members (Sharifian, 2013). In addition, Iranian EFL learners due to their own cultural, religious and social upbringing are constantly reminded of the consequences of their thoughts and behavior in terms of what others may say or think about them.

Was there anything in the situations that you felt you should consider, like when making a request/apology-was anything particularly important about the situations?

(1) I think I had to be polite because I wanted an extension for my assignment. I knew I was writing to my professor but I could not find the right words.

(2) Everybody expects a female student to be polite, obedient and careful. Not a...

(3) Some of the situations were embarrassing and I felt more involved. I was trying to be formal in my requests and sincere in my apologies. I wanted to be polite. 
EFL learners with high linguistic competence feel worried about their lack of pragmatic competence. They perceived the verbalization of the speech acts as one of incurring indebtedness or asserting a reciprocal social relationship, as is often the case in their L1s and this very often entails an obligation not only for the speaker, but also for the hearer to comply.

(1) The lecturer is older has a high social status and is completely different to a friend so I have to be more formal I do not know how the English people say to the teacher. My professors' reaction is important. I do not know...

The verbal reports provided timely insights into current states of the learners' socio-pragmatic knowledge and the sources of that knowledge (Ren, 2013). Evidently, the learning environment (Hassall, 2008; Woodfield, 2012) influences the EFL learners' knowledge and this can be a significant factor in the development of L2 pragmatic awareness. Culturally based differences occur when language learners need to perform a particular speech act they will select from a variety of strategies and linguistic forms that are based upon the social norms and linguistic forms that characterize their first language. In line with Cook (1999), it is clear that the context that the student brings to understand a message may differ among individuals because of their internal states and cognitive abilities. L2 users are not failed native speakers. As Kesckes (2015) observed, "Socio-pragmatic norms and conventions concerning appropriateness developed through L1 are very influential and difficult to change. Exposure to and immerging into the new language and culture are not enough to change them" (p. 3).

- Just imagine telling your lecturer you spilt tea on his book. No, I will never apologize. I may even have a few courses the next semester. I will replace the spoilt book with a new one. He is my superior. I should respect him. (Female participant).

The RVRs show that a speaker needs to reconsider a series of factors that may have an influence on his/her assumption of responsibility, and therefore emphasize his/her innocence by not feeling the need to apologize. Dorneyi (2009) believed that L2 learners are engaged in an ongoing appraisal and response process, involving their continuous monitoring, evaluating how well they are doing in a task, and then making possible amendments if something seems to be going amiss. According to Beeman (2001), affectivity is a communicative dimension in language that is by nature systemic. Sincerity is the assessment by addressees in that the expressions are true representations of their feelings and emotional state. For Iranians, power and status relations between addressers and addressees are of paramount importance, as are settings in which emotional display of language takes place. To be more explicit, a person in order to present the self, will definitely chose the language in a particular situation. Individuals have their own beliefs and principles regarding language and the way they would like to identify themselves; their linguistic choices clearly affect learners' comprehension of pragmatic meaning. Positive face is a person's desire to be approved of by selected others whereas negative face relates to the desire to act according to one's will despite their disapproval of one's chosen course of action. Evidently, in all social interactions every individual cultivates a sense of self-identity that is expressed through the language he/she chooses to use. This identity is largely dynamic in that, it constantly changes according to the interlocutor (s), the social situation and the context. Identity is not simply given but built up through symbolic interactions and the use of language is entailed in the process of identity construction. The learning and use of a language other than the L1 is bound to have an impact on the person as a whole. Accepting or rejecting the L2 norms and patterns of social interaction need conscious acts by the language learner and the selection of the appropriate form and strategies that are likely to be constrained by L1cultural communicational patterns.

\section{Conclusion and Implications}

In sum, the verbal reports showed how learners create and test different hypotheses about the nature of the target pragmatic structure. Overall findings indicated that students' evaluation of the situational variations helped in their assessment of the speech act situations and in their ability to make adjustments in accordance with the contextual variables of social power, social distance and degree of imposition/severity of offence. Qualitative analyses showed the strong interaction of learner subjectivity with the learner variables of language proficiency, gender and age relating to learners' sociopragmatic knowledge and ways in which such assessment mediated pragmalinguistic choices. The RVRs identified occasions where learners intentionally either accommodated to or resisted perceived L2 pragmatic norms, and probed how they arrived at those decisions. While the participants largely converged toward L2 norms to emulate the target language pragmatic norms, occasionally intentional divergence from L2 norms was evident in their resistance to pragmatic uses of salutations and higher-level honorifics. They may sometimes feel inhibited in adopting certain TL norms that are foreign to their own cultural behavior patterns and may refrain from performing according to patterns they are taught. Their agency can be accounted for in terms of speech accommodation theory (Beebe \& Giles, 1984) which views pragmatic decisions as an enactment of social, psychological, and affective dispositions.

- Whatever I say, an English person will look at me as an Iranian. I like English and I like Persian. Persian is my mother tongue. No, I cannot and I will never say 'Dear' to a male lecturer.

From the RVRs, it can be understood that the task of learning English is much more than learning a set of grammatical rules and lexical items for those speakers of Persian whose general communicative behavior is governed by Persian schemas (Sharifian, 2013). Psychological and socio-cultural notions of what is polite and appropriate differ widely among languages and strategies for pragmatic behavior are closely tied to self-identity and social identity. O'Shea (2000) believed that, "All Iranians measure themselves to a great extent by the honor they accumulate through their actions and social interrelations" (p. 101). Context is a reflection of one's cognitive state because it contains all the facts that one is aware of or is capable of becoming aware of, however, once learners have a good understanding of certain 
L2 pragmatic norms, it should remain their prerogative to decide whether to emulate or resist them (Ishihara, 2008). RVRs can help the EFL teacher to move away from a focus on language forms alone to a focus on pragmatics, i.e. how language is used to do things in social contexts. Through determining the source of a particular speech act behavior, understanding these values and attitudes are essential to ensure that learners can interpret interactions as intended by their interlocutor and communicate their message exactly as they wish in the L2.

\section{References}

Bardovi-Harlig, K. \& Dornyei, Z. (1998). Do language learners recognize pragmatic violations? Pragmatic versus grammatical awareness in instructed L2 learning. TESOL Quarterly, 32 (2), 233-262. http://dx.doi.org/10.2307/3587583

Bardovi-Harlig, K. \& Hartford, B. S. (1990). Congruence in native and nonnative conversations: Status balance in the academic advising session. Language Learning, 40 (4), 467-501. http://dx.doi.org/10.1111/j.1467-1770.1990.tb00603.x

Bardovi-Harlig, K. \& Hartford, B. S. (2005). Interlanguage pragmatics: Exploring institutional talk. Mahwah, NJ: Lawrence Erlbaum Associates, Publishers.

Beebe, L. \& Giles, H. (1984). Speech accommodation theories: A discussion in terms of second language acquisition. International Journal of the Sociology of Language, 46, 5-32. http://dx.doi.org/10.1515/ijs1.1984.46.5,

Beeman, W. (2001). Emotion and sincerity in Persian discourse: Accomplishing the representation of inner states. International Journal of the Sociology of Language, 148, 31-57. http://dx.doi.org/10.1515/ijs1.2001.013,

Bergman, M. L. \& Kasper, G. (1993). Perception and performance in native and nonnative apology. In G. Kasper, \& S. Blum-Kulka (Eds.), Interlanguage pragmatics (pp.82-107). NY: Oxford University Press.

Bialystok, E. (1993). Symbolic representation and attentional control in pragmatic competence. In G. Kasper, \& S. Blum-Kulka (Eds.), Interlanguage pragmatics (pp. 43-57). Oxford: Oxford University Press.

Blum-Kulka, S., House, J. \& Kasper, G. (Eds.). (1989). Cross-cultural pragmatics: Requests and apologies. Norwood, NJ: Ablex.

Camps, J. (2003). Concurrent and retrospective verbal reports as tools to better understand the role of attention in second language tasks. International Journal of Applied Linguistics, 13 (2), 201-221. http://dx.doi.org/10.1111/14734192.00044

Cohen, A. D. (2013). Verbal reports. In C. A. Chapelle (Ed.), The encyclopedia of applied linguistics (pp. 1-5). Blackwell Publishing Ltd. doi: 10.1002/9781405198431.wbeal1261

Cohen, A. D. \& Olshtain, E. (1993). The production of speech acts by EFL learners. TESOL Quarterly, 27(1), 33-56. http://dx.doi.org/ 10.2307/3586950

Cook, V. (1999). Going beyond the native speaker in language teaching. TESOL Quarterly, 33(2), 185-209. http://dx.doi.org/ 10.2307/3587717

Dorneyi, Z. (2009). Individual differences: Interplay of learner characteristics and learning environment. Language Learning, 59 (Suppl. 1), 230-248. http://dx.doi.org/ 10.1111/j.1467-9922.2009.00542.x

Ellis, R. (2008). The study of second language acquisition. Oxford: Oxford University Press.

Ericsson, K. A. \& Simon, H. A. (1993). Protocol analysis. Cambridge MA: The MIT Press.

Fe'lix-Brasdefer, C. (2006). Speech act perception in interlanguage pragmatics: Exploring the minds of foreign language learners. Series A: General \& Theoretical Papers No. 652. University Duisburg-Essen: Essen.

Fe'lix-Brasdefer, C. (2008). Perceptions of refusals to invitations: Exploring the minds of foreign language learners. Language Awareness, 17, 195-211. http://dx.doi.org/ 10.1080/09658410802146818

Fukushima, S. (2000). Requests and culture. Bern: Peter Lang.

Gass, S. \& Mackey, A. (2000). Stimulated recall methodology in second language research. Mahwah, NJ: Lawrence Erlbaum.

Haji Maibodi, A. (2016). Assessing the impact of individual differences on the interlanguage pragmatics of the Iranian EFL learner in institutional discourse. Tehran, Iran: Science and Research Branch, PhD dissertation.

Hassall, T. (2008). Pragmatic performance: What are learners thinking? In E. Alcon Soler, \& A. Martinez-Flor (Eds.), Investigating pragmatics in foreign language learning, teaching and testing (pp. 72-93). Bristol, Avon: Multilingual Matters.

Horwitz, E. K. (1999). Cultural and situational influences on foreign language learners' beliefs about language learning: A review of BALLI studies. System, 27, 557-576. http://dx.doi.org/ 10.1016/S0346-251X (99)00050-0

Ishihara, N. (2006). Subjectivity, second/foreign language pragmatic use, and instruction: Evidence of accommodation and resistance. Department of Curriculum and Instruction, University of Minnesota, PhD Dissertation.

Ishihara, N. (2008). Transforming community norms: Potential of L2 speakers' pragmatic resistance. Proceedings of the 2008 Colloquium on Applied Linguistics. Japan: Temple University.

Jourdenais, R. (2001). Cognition, instruction and protocol analysis. In Peter Robinson (Ed.), Cognition and second language instruction (pp. 354-375). Cambridge: Cambridge University Press. 
Kasper, G. \& Rose, K. R. (2002). Individual differences in pragmatic development. In G. Kasper, \& K. R. Rose (Eds.), Pragmatic development in a second language (pp. 275 -303). Michigan: Blackwell.

Kasper, G. \& Dahl, M. (1991). Research methods in interlanguage pragmatics. Studies in Second Language Acquisition, 13, 215-247. http://dx.doi.org/10.1017/S0272263100009955

Kecskes, I. (2015). How does pragmatic competence develop in bilinguals? International Journal of Multilingualism. http://dx.doi.org/ 10.1080/14790718.2015.1071018

Kormos, J. (1998). The use of verbal reports in L2 research. TESOL Quarterly, 32(3), 353-362. http://dx.doi.org/ $10.2307 / 3587590$

Leech, G. N. (1983). Principles of pragmatics. London: Longman.

van Lier, L. (2008). Agency in the classroom. In J. P. Lantolf, \& M. E. Poehner (Eds.), Sociocultural theory and the teaching of second languages (pp.163-186). London, U.K.: Equinox Publishing Ltd.

LoCastro, V. (2003). An introduction to pragmatics: Social action for language teachers. Ann Arbor, MI: University of Michigan Press.

Nisbett, R. E. \& Wilson, T. D. (1977). Telling more than we can know: Verbal reports on mental processes. Psychological Review, 84, 231-59. http://dx.doi.org/10.1037/0033-295X.84.3.231

Norton, B. (1997). Language, identity, and the ownership of English. TESOL Quarterly, 31 (3), 409-429. http://dx.doi.org/ 10.2307/3587831

Norton, B. \& Toohey, K. (2011). Identity, language learning, and social change. Language Teaching, 44 (4), $412-446$. (State-of-the-Art Article). http://dx.doi.org/10.1017/S0261444811000309

O’Shea, M. (2000). Cultural shock: Iran. Portland, Oregon: Graphic Arts Publishing Company.

Ren, W. (2013). A longitudinal investigation into L2 learners' cognitive processes during study abroad. Applied Linguistics, 35(5), 575-594. http://dx.doi.org/ 10.1093/applin/amt019

Rose, K. R. (2000). An exploratory cross-sectional study of interlanguage pragmatic development. Studies in Second Language Acquisition, 22, 27-67.

Schauer, G. A. (2006). The development of ESL learners' pragmatic competence: A longitudinal investigation of awareness and production. In K. Bardovi-Harlig, C. Fe'lix-Basdefer, \& A. Omar (Eds.), Pragmatics and language learning (pp.135-164). Manoa, HI: Second Language Teaching and Curriculum Center University of Hawaii.

Schmidt, R. (1993). Consciousness, learning and interlanguage pragmatics. In G. Kasper, \& S. Blum-Kulka (Eds.), Interlanguage pragmatics (pp. 21-42). Oxford: Oxford University Press.

Seliger, H. (1983). The language learner as linguist: Of metaphors and realities. Applied linguistics, 4(3), $179-91$. http://dx.doi.org/ 10.1093/applin/4.3.179

Sharifian, F. (2013). Cultural conceptualizations in learning English as an L2: Examples from Persian-speaking learners. Iranian Journal of Language Teaching Research, 1 (1), 90-116.

Swain, M. (1985). Communicative competence: Some roles of comprehensible input and comprehensible output in its development. In S. Gass, \& C. Madden (Eds.), Input in second language acquisition (pp. 235-253). Rowley, MA: Newbury House.

Swain, M. (1995). Three functions of output in second language learning. In G. Cook, \& B. Seidlhofer (Eds.), Principle and practice in applied linguistics: Studies in honor of H.G.Widdowson (pp. 125-144). Oxford: Oxford University Press.

Trosborg, A. (1995). Interlanguage pragmatics: Requests, complaints and apologies. Berlin; New York: Mouton de Gruyter.

Usó -Juan, E. (2010). Requests: A sociopragmatic approach. In A. Martinez-Flor, \& E. Usó -Juan (Eds.), Speech act performance: Theoretical, empirical and methodological issues (pp. 237-256). Amsterdam: John Benjamins Publishing Company.

Usó-Juan, E., \& Martínez-Flor, A. (2014). Reorienting the assessment of the conventional expressions of complaining and apologizing: From single-response to interactive DCTs. Iranian Journal of Language Testing, 4(1), 113-136.

Weedon, C. (1997). Feminist practice and poststructuralist theory. London: Blackwell.

Woodfield H. P. (2010). What lies beneath? Verbal report in interlanguage requests in English. Multilingua, 29 (1), 127. http://dx.doi.org/ 10.1515/mult.2010.001

Woodfield, H. P. (2012). Pragmatic variation in learner perception: the role of retrospective verbal report in L2 speech act research. In J. C. Felix-Brasdefer, \& D. Koike (Eds.), Pragmatic Variation in First and Second Language Contexts: Methodological Issues. (Vol. Impact: Studies in Language and Society, pp. 209- 237). Amsterdam/Philadelphia: John Benjamins.

Woodfield, H. \& Economidou-Kogetsidis, M. (2010). 'I just need more time': A study of native and non-native requests to faculty for an extension. Multilingua, 29 (1), 77-118. http://dx.doi.org/ 10.1515/mult.2010.004 